\title{
Análise da eficiência da tinta de base epoxídica na proteção do concreto leve com argila expandida contra o ataque por ácido sulfúrico
}

\author{
Analysis of epoxy based paint efficiency in \\ expanded clay lightweight concrete protection of \\ sulfuric acid attack
}

Felipe de Souza Abreu ${ }^{1}$, Carmen Couto Ribeiro ${ }^{2}$, Joana Darc Silva Pinto ${ }^{3}$, Danielle Meireles Oliveira ${ }^{4}$, Sidnea Eliane Campos Ribeiro ${ }^{5}$, Ênio José Pazini Figueiredo ${ }^{6}$

\begin{abstract}
${ }^{1}$ Escola de Engenharia da Universidade Federal de Minas Gerais - UFMG, Av. Antônio Carlos, 6627, Bloco 02, Sala 2230, Pampulha, CEP: 31.270-901, Belo Horizonte, MG, Brasil.

2,4,5 Escola de Engenharia da Universidade Federal de Minas Gerais - UFMG. Av. Antônio Carlos, 6627, Bloco 01, Sala3305, Pampulha, CEP: 31.270-901, Belo Horizonte, MG, Brasil.

${ }^{3}$ Departamento de Engenharia Civil da Pontifícia Universidade Católica de Minas Gerais, PUC Minas, Av. Dom José Gaspar, 500 -Coração Eucarístico, CEP: 30.535-610, Belo Horizonte, MG, Brasil.

${ }^{6}$ Escola de Engenharia Civil e Ambiental da Universidade Federal de Goiás - UFG, Praça Universitária, s/n, Setor Universitário, CEP: 74605-22, Goiânia, GO, Brasil.

e-mail:felipesouza_15@hotmail.com, carmencouto@oi.com.br;daniellemdo@gmail.com, sidneaecr@gmail.com, joanadarc@pucminas.br, epazini@terra.com.br
\end{abstract}

\section{RESUMO}

Este trabalho tem como objetivo realizar uma análise da eficiência da tinta de base epoxídica utilizada como proteção superficial do concreto leve com argila expandida submetido ao ataque por ácido sulfúrico $\left(\mathrm{H}_{2} \mathrm{SO}_{4}\right)$. Ataques ácidos externos podem promover reações expansivas e a degradação acelerada, comprometendo assim a durabilidade das estruturas de concreto leve. Dentre as proteções desenvolvidas, as tintas têm um importante destaque, por possuírem boa aderência à superfície do concreto, serem resistentes ao intemperismo e à fotodegradação, além de apresentar boa estabilidade química. O desempenho da tinta de base epoxídica foi avaliado por meio de inspeção visual e de ensaios de resistência à compressão, absorção de água e perda de massa do concreto antes e após ataque químico. A avaliação por inspeção visual demonstrou que os corpos de prova de concreto leve com proteção superficial epoxídica apresentaram uma diminuição da perda de coesão da pasta causada pelo ataque. Os resultados dos ensaios de absorção de água, de perda de massa e de resistência mecânica demonstraram o bom desempenho da tinta de base epoxídica, impedindo a penetração do agente agressivo nos concretos protegidos. A pesquisa permite concluir que a proteção epoxídica reduz significativamente o impacto causado pelo ácido sulfúrico ao concreto e que pode garantir a durabilidade das estruturas confeccionadas com concretos leves de argila expandida.

Palavras-chave: concreto leve, durabilidade, tinta epoxídica.

\section{ABSTRACT}

The purpose of this study is to analyze the efficiency of epoxydic base paint used as a protective coating on expanded clay lightweight concrete under sulfuric acid $\left(\mathrm{H}_{2} \mathrm{SO}_{4}\right)$ attack. External attacks can promote expansions and accelerated degradation, reducing the concrete durability. Developed protections, such as paints have an important performance result, because they have good adhesion to the concrete surface, weathering and photodegradation resistant, besides provide a good chemical stability. The performance of epoxydic paint was assessed through visual inspection, compressive strength test, water absorption and mass losses before and after chemical attack. The visual inspection demonstrated that the epoxy-coated lightweight concrete specimens had a clear reduction in the loss of cohesion of the paste caused by the attack. The teste results of regarding water absorption, mass loss and mechanical strength showed the good performance of the epoxydic base paint, preventing the penetration of the aggressive agent on protected concretes. This research shows that 
epoxydic protection reduces the impact of external acid attacks on concrete and can improve the durability of expanded clay lightweight concrete structures.

Keywords: lightweight concrete, durability, epoxydic paint.

\section{INTRODUÇÃO}

A utilização do concreto leve está se ampliando pelo aumento da utilização de elementos pré-moldados, permitindo uma diminuição nos custos de transporte e uma maior facilidade de aplicação, por apresentar menor massa específica. O peso próprio dos elementos de concreto convencional é elevado e pode representar importante parcela da carga total a ser suportada por uma estrutura. A utilização de lajes de concreto leve pode resultar na diminuição das cargas relativas aos elementos estruturais com menores seções transversais e em uma correspondente diminuição nas fundações [1].

O concreto com agregados leves, ou concreto leve estrutural, apresenta-se como um material de grande potencial de aplicação em diversas áreas da construção civil. A utilização desse material em todo o mundo é particularmente atribuída aos benefícios promovidos pela redução da massa específica do concreto e, consequentemente, redução de esforços na estrutura das edificações, economia com formas e cimbramento, bem como diminuição dos custos com transporte e montagem de construções pré-fabricadas $[1,2,3]$.

O concreto leve é um material que pode ser utilizado na construção de edificações de múltiplos pavimentos, pontes, estruturas pré-fabricadas e em estruturas flutuantes, como tanques e plataformas. Atualmente, devido ao déficit de agregados leves naturais que podem ser obtidos através do tratamento térmico de matérias primas naturais como, folhelho, vermiculita e ardósia ou de subprodutos industriais como a escória de alto forno, os agregados leves de argila expandida aparecem como uma das melhores opções de agregado leve para a produção de concretos estruturais leves no Brasil [3, 4].

A argila expandida é produzida através do aquecimento de tipos específicos de argila a uma temperatura próxima de $1200^{\circ} \mathrm{C}$, incorporando na massa gases liberados pela decomposição química de uma parte do material. Este processo gera a expansão da argila e consequentemente o baixo peso específico devido à formação de espaços vazios no seu interior. O agregado de argila expandida é um material de forma esférica, superfície rugosa, massa interna celular altamente porosa, inerte, de alta absorção, bom isolante termoacústico e de boa resistência mecânica, apesar da baixa massa específica [5, 6].

A resistência aos esforços mecânicos do agregado, cujo valor é influenciado pela porosidade de seus grãos, deve ser superior à da pasta de cimento para que estes não se rompam primeiro. Os agregados utilizados na produção do concreto convencional são em geral mais densos e resistentes quando comparados aos agregados leves que, em geral, são mais porosos $[6,7,8]$.

O Guia de Concreto Estrutural feito com agregado leve, publicado pelo American Concrete Institute - 213R-14:2014 [9], define concreto estrutural com agregado leve como concreto com resistência à compressão aos 28 dias acima de $17 \mathrm{MPa}$ e massa específica, na condição seca ao ar, não excedendo $1.850 \mathrm{~kg} / \mathrm{m}^{3}$. Estes valores são corroborados pela ABNTNM $35: 1995$ [10].

AABNT NBR 6118:2014 [11], que trata de projeto de estruturas de concreto armado, leva em consideração a utilização de concretos compatíveis para cada tipo de ambiente. A norma faz uma correspondência entre a classe de agressividade ambiental e a qualidade do concreto correlacionando a resistência à compressão e a relação água-cimento com a agressividade do meio, visando a durabilidade do concreto. Estas características podem ser obtidas por um consumo adequado de cimento, uma trabalhabilidade condizente com a utilização proposta e um cobrimento mínimo, caso o concreto seja armado $[1,2,5,6]$.

Na Europa e na América do Norte, profissionais contabilizaram seus custos de manutenção em estruturas de concreto em um passado recente e adotaram novos procedimentos tecnológicos, visando maior durabilidade. Estudos realizados concluíram, então, pela necessidade de redução da água total nos traços do concreto, para aumentar a resistência, reduzir a fissuração e a deformabilidade, fatores apontados como causas de patologias que podem reduzir a durabilidade prevista [12].

Considerando o uso do concreto em condições adversas de exposição, medidas especiais de proteção e conservação devem ser tomadas, tais como a aplicação de revestimentos hidrofugantes e pinturas impermeabilizantes sobre a superfície do concreto. Dentre as pinturas impermeabilizantes, as tintas vêm sendo amplamente empregadas devido à facilidade de aplicação e à boa aderência ao concreto $[13,16]$.

Uma forma de degradação do concreto resultante de reações químicas entre o cimento Portland hidratado e sulfatos de fontes externas pode se manifestar na forma de expansão, provocando a sua fissuração, aumentando a sua permeabilidade e facilitando a penetração do agente agressivo. $\mathrm{O}$ ataque por sulfato pode provocar a perda progressiva de massa e de resistência, devido ao ataque do sulfato ao $\mathrm{C}_{3} \mathrm{~A}$ do cimento Portland. Estas formas de deterioração do concreto dependem da concentração dos sulfatos presentes nos agentes de contato, do tipo de cimento, da sua composição e das proporções de mistura do concreto [6]. A resistência à compressão pode ser afetada pela degradação, e quanto maiores as perdas, maior a 
necessidade de promover a proteção deste concreto $[14,15]$.

Avanços ocorridos na ciência química têm possibilitado o desenvolvimento de inúmeros tipos de proteção que permitem estender a durabilidade do concreto com a redução da absorção de água e da penetração de sais e de agentes agressivos, desde que as proteções propostas sejam periodicamente inspecionadas para verificação da necessidade de renovação, a fim de manter sua funcionalidade [13].

Dentre as proteções desenvolvidas, as tintas têm um papel de destaque porque, quando aplicadas, aderem à superfície do concreto, formando um filme contínuo de baixa permeabilidade. As tintas devem oferecer proteção contra os principais agentes agressivos, ao intemperismo e à fotodegradação, evitando o desenvolvimento de fungos e bactérias, além de oferecer resistência a pequenos impactos e riscos. As tintas devem apresentar, também, estabilidade química em relação ao concreto, de forma a evitar a ocorrência de eflorescências, saponificação e outras anomalias decorrentes da elevada alcalinidade do substrato [13].

A tinta epoxídica para estruturas de concreto apresenta bom poder de cobertura, além de formar uma película que, depois de curada, oferece resistências química e mecânica. Além disso, possui boa resistência à abrasão provocada pelo tráfego e vários tipos de ataques químicos, como os causados por soluções de ácidos e álcalis, gorduras e óleos combustíveis [16].

Nesse contexto, o concreto leve por suas características intrínsecas é mais vulnerável a agentes agressivos do que o concreto com agregados tradicionais. O propósito deste trabalho é analisar a eficiência da proteção epoxídica no aumento da impermeabilidade do concreto leve, uma vez que este tema não tem sido abordado em trabalhos recentes. A utilização estrutural do concreto leve pode ser ampliada através do ganho de durabilidade em relação a agentes externos, portanto o estudo comparativo do concreto leve com argila expandida em relação ao concreto convencional, ambos sem e com a aplicação de uma proteção epoxídica, submetidos a um meio agressivo ácido, tem como objetivo avaliar a eficiência da camada protetora na minimização da degradação do ataque por ácido sulfúrico ao concreto leve, o que pode promover maior durabilidade às estruturas moldadas com este tipo de concreto.

\section{MATERIAIS E MÉTODOS}

Esta pesquisa compara as propriedades mecânicas e físicas de um concreto leve produzido com argila expandida 1506 (CINEXPLAN) e um concreto convencional de brita de gnaisse protegidos ou não por uma camada de tinta epoxídica, submetidos à ação de agente agressivo ácido. Os materiais constituintes dos concretos foram caracterizados no Laboratório de Materiais do Departamento de Materiais de Construção da Universidade Federal de Minas Gerais - DEMC/UFMG.

Para a produção do concreto leve, uma pré-saturação da argila expandida foi realizada durante 24 horas para compensar a taxa de absorção de água, diminuir o material pulverulento e melhorar a trabalhabilidade do concreto. A taxa de absorção de água do agregado leve foi medida e a quantidade foi descontada na água de amassamento, mantendo constante a relação água/cimento do estudo de dosagem. Este procedimento foi adotado conforme métodos experimentais observados em trabalhos anteriores [3, 4].

Os corpos de prova cilíndricos de $10 \mathrm{~cm}$ x $20 \mathrm{~cm}$ foram moldados e rompidos de acordo com as normas ABNT NBR 5738:2016 e ABNT NBR 5739:2007. Os corpos de prova foram desformados após 24 horas e colocados na câmara úmida até a data de rompimento [26,27].

Após 28 dias de cura submersa, os corpos de prova foram secos e alguns deles protegidos com camada protetora de tinta epoxídica como proteção suplementar, visando comparar concretos protegidos e concretos sem proteção submetidos ao ataque por ácido sulfúrico. Conforme definido no manual de aplicação da tinta epoxídica, a superfície áspera do concreto estava seca, limpa, isenta de pó. A camada protetora foi aplicada em 2 demãos, com trincha e intervalo mínimo de 24 horas entre as demãos. A secagem das proteções teve uma duração de oito dias, em local ventilado e em condições normais de temperatura $\left(25 \pm 5^{\circ} \mathrm{C}\right)[28]$.

Uma vez atingidas as condições necessárias a uma boa proteção, o ataque nos concretos foi feito por imersão em solução de ácido sulfúrico $\left(\mathrm{H}_{2} \mathrm{SO}_{4}\right)$, durante 7 dias, com o objetivo de simular ataques acelerados a estruturas de concreto, visando compará-los a efeitos decorrentes de sua exposição a meios agressivos ao longo do tempo. Todos os corpos de prova foram imersos após 36 dias de idade, sendo 28 dias de cura submersa e 8 dias para secagem dos corpos de prova que receberam a proteção epoxídica. Este ensaio foi adaptado conforme preconizado pela ABNT NBR 13583: 2014 [30].

A degradação dos concretos foi avaliada após 43 dias de idade, sendo 28 dias de cura, 8 dias de secagem da proteção epoxídica e 7 dias de imersão em ácido sulfúrico. De maneira preliminar foi realizado ensaio de inspeção visual dos corpos de prova, conforme características indicadas pela ABNT NBR 6118:2014 [11]. Os demais ensaios realizados foram: medida 
da taxa de absorção, medida da perda de massa (conforme procedimento desenvolvido em trabalhos anteriores) e da perda de resistência à compressão em corpos de prova de concreto sem e com proteção [15, 27, 29].

\section{RESULTADOS E DISCUSSÃO}

Os resultados dos ensaios de caracterização do cimento CPII-E-32, utilizado na produção dos corpos de prova, são apresentados na Tabela $1[17,18,19,20]$.

Tabela 1: Resultados dos ensaios de caracterização física do cimento CP II-E-32.

\begin{tabular}{c|c|c|c|c|c}
\hline Cimento & $\begin{array}{c}\text { Massa } \\
\text { unitária } \\
\left(\mathbf{k g} / \mathbf{d m}^{3}\right)\end{array}$ & $\begin{array}{c}\text { Massa } \\
\text { Específica } \\
\left(\mathbf{k g} / \mathbf{d m}^{3}\right)\end{array}$ & $\begin{array}{c}\text { Finura Método } \\
\text { Blaine }\left(\mathbf{m}^{\mathbf{2}} \mathbf{k g}\right)\end{array}$ & $\begin{array}{c}\text { Finura peneira } \\
\left.\mathbf{n}^{\mathbf{0}} \mathbf{2 0 0 - 7 5} \mathbf{\mu m} \mathbf{( \% )}\right)\end{array}$ & $\begin{array}{c}\text { Expansibilidade a } \\
\text { frio }(\mathbf{m m})\end{array}$ \\
\hline CP II-E-32 & 1,1 & 3,1 & 310,0 & 2,5 & 0,0 \\
\hline
\end{tabular}

Na Tabela 2, são apresentadas as características físicas dos agregados utilizados no trabalho. [21, 22, 23, 24].

Tabela 2: Resultados dos ensaios de caracterização física dos agregados.

\begin{tabular}{|c|c|c|c|c|c|}
\hline Agregado & $\begin{array}{c}\text { Massa } \\
\text { Unitária }(\mathbf{k g} / \\
\left.\mathrm{dm}^{3}\right)\end{array}$ & $\begin{array}{c}\text { Massa } \\
\text { Específica } \\
\left(\mathbf{k g} / \mathrm{dm}^{3}\right)\end{array}$ & $\begin{array}{l}\text { Módulo de } \\
\text { Finura }\end{array}$ & $\begin{array}{l}\text { Dimensão máxima } \\
\text { Característica }(\mathrm{mm})\end{array}$ & $\begin{array}{c}\text { Absorção de água } \\
(\%)\end{array}$ \\
\hline $\begin{array}{c}\text { Areia Lavada } \\
\text { Média }\end{array}$ & 1,4 & 2,6 & 2,8 & 4,8 & - \\
\hline Brita de Gnaisse & 1,5 & 2,7 & 6,3 & 12,5 & $<1,0$ \\
\hline Argila Expandida & 0,7 & 1,4 & 6,7 & 12,5 & 8,9 \\
\hline
\end{tabular}

A Figura 1 apresenta a curva granulométrica da areia lavada média empregada na confecção do concreto [25].

CURVAS GRANULOMÉTICAS

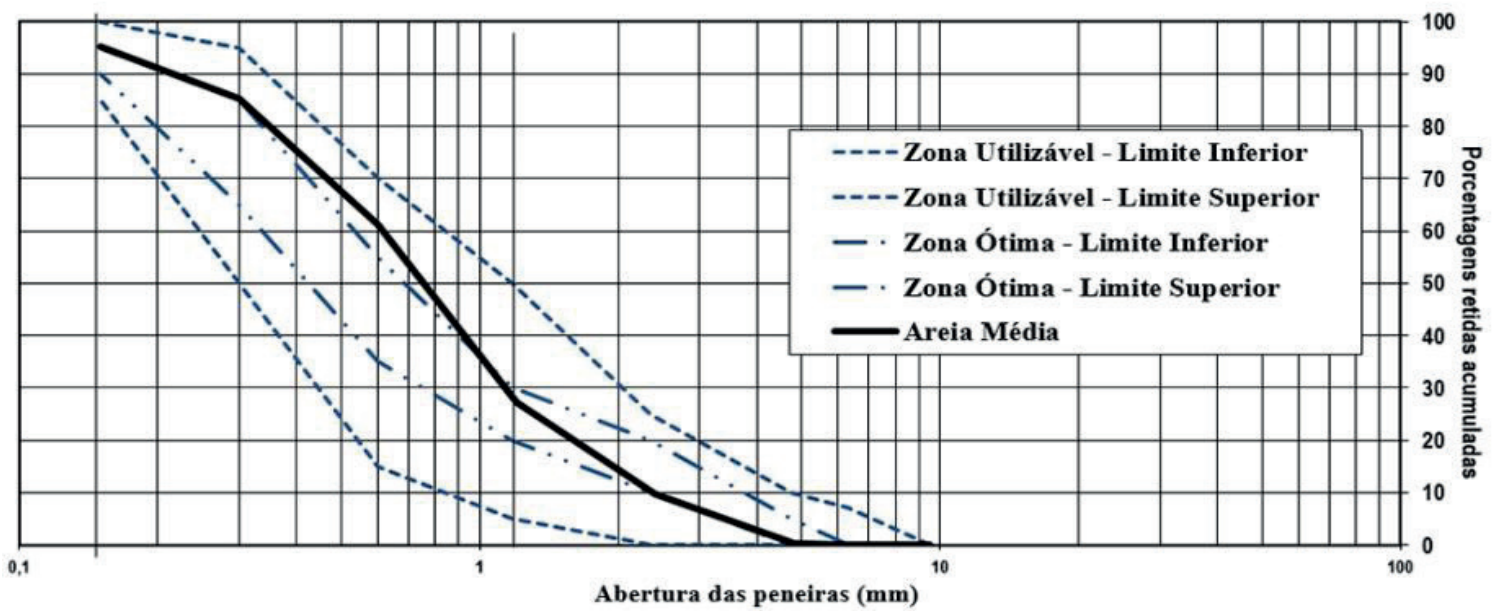

Figura 1: Curva granulométrica da areia e limites da zona utilizável e da zona ótima [25].

As curvas granulométricas da argila expandida e da brita de gnaisse empregadas na confecção dos concretos estão representadas na Figura 2 [25]. 
CURVAS GRANULOMÉTICAS

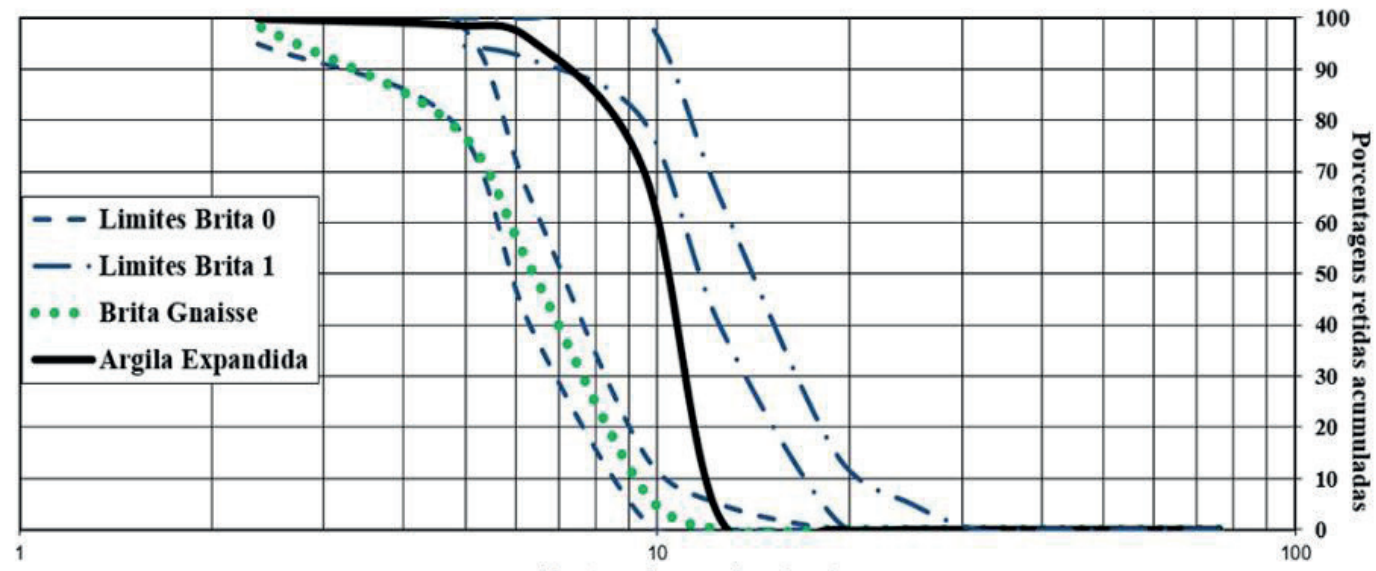

Abertura das peneiras (mm)

Figura 2: Curvas granulométricas da argila expandida e da brita de gnaisse comparadas às curvas das britas 0 e 1 [25].

Uma vez realizada a caracterização dos materiais constituintes, as dosagens foram realizadas de modo a selecionar um concreto convencional de referência a ser comparado com o concreto leve com argila expandida. O concreto selecionado foi especificado com um consumo de cimento de $370 \mathrm{~kg} / \mathrm{m}^{3}$, uma relação água/cimento de $0,50 \mathrm{e} 1 \%$ de aditivo plastificante em relação à massa de cimento. As dosagens do concreto convencional e do concreto leve com argila expandida atenderam ao valor mínimo de resistência característica à compressão para a classe de concreto $\mathrm{C} 40$ e relação água-cimento de 0,50, estabelecidos pela ABNT NBR 6118:2014, para concretos a serem submetidos à agressividade da classe III [11]. A composição dos concretos avaliados está na Tabela 3.

Tabela 3: Consumo de materiais para produzir $1 \mathrm{~m}^{3}$ de concreto.

\begin{tabular}{c|c|c|c|c|c}
\hline Concreto & $\begin{array}{c}\text { Consumo de } \\
\text { Cimento }(\mathrm{kg})\end{array}$ & $\begin{array}{c}\text { Consumo de } \\
\text { areia }(\mathrm{kg})\end{array}$ & $\begin{array}{c}\text { Consumo de } \\
\text { brita }(\mathrm{kg})\end{array}$ & $\begin{array}{c}\text { Consumo de argila } \\
\text { expandida }(\mathrm{kg})\end{array}$ & Aditivo (\%) \\
\hline Convencional & 370,0 & 740,0 & $1.100,0$ & - & 1,0 \\
\hline Argila expandida & 370,0 & 740,0 & - & 513,0 & 1,0 \\
\hline
\end{tabular}

Os traços em massa e em volume são apresentados na Tabela 4, sendo o volume da brita de gnaisse substituído totalmente pela argila expandida no caso do concreto leve.

Tabela 4: Traços unitários de concreto em massa e em volume.

\begin{tabular}{c|c|c|c}
\hline Concreto & Traço em massa $(\mathrm{kg})$ & traço em massa/ volume $\left(\mathrm{kg} / \mathrm{dm}^{3}\right)$ & Relação água/cimento \\
\hline Convencional & $1,0: 2,0: 3,0$ & $1,0: 1,4: 2,0$ & 0,50 \\
\hline Argila expandida & $1,0: 2,0: 1,4$ & $1,0: 1,4: 2,0$ & 0,50 \\
\hline
\end{tabular}

Os resultados de resistência à compressão, inspeção visual, absorção de água, perda de massa e de resistência à compressão sem e com proteção epoxídica, antes e após ataque por ácido sulfúrico, são apresentados a seguir. Todos os resultados foram obtidos para corpos de prova com 43 dias de idade, sendo 28 dias de cura, 8 dias de secagem da proteção epoxídica e 7 dias de imersão em meio ácido.

Na Tabela 5, são apresentadas as resistências à compressão antes do ataque por ácido, aos 7 e 28 dias de cura do concreto convencional e do concreto leve com argila expandida produzidos com $370 \mathrm{~kg}$ de cimento, relação água/cimento de 0,50 e $1 \%$ de aditivo plastificante polifuncional, conforme descrito na metodologia. 
Tabela 5: Resistência à compressão aos 7 e 28 dias do concreto convencional e do concreto leve sem proteção epoxídica durante o estudo comparativo de dosagem.

\begin{tabular}{c|c|c|c}
\hline \multirow{2}{*}{ Concreto } & \multirow{2}{*}{ Relação água/cimento } & \multicolumn{2}{|c}{ Resistência à compressão (MPa) } \\
\cline { 3 - 4 } & & 7 Dias & 28 Dias \\
\hline Convencional & 0,50 & 28,0 & 40,0 \\
\hline Argila expandida & 0,50 & 21,0 & 30,0 \\
\hline
\end{tabular}

A Figura 3 apresenta graficamente as respectivas tendências de evolução da resistência à compressão do concreto convencional e do concreto leve sem proteção epoxídica.

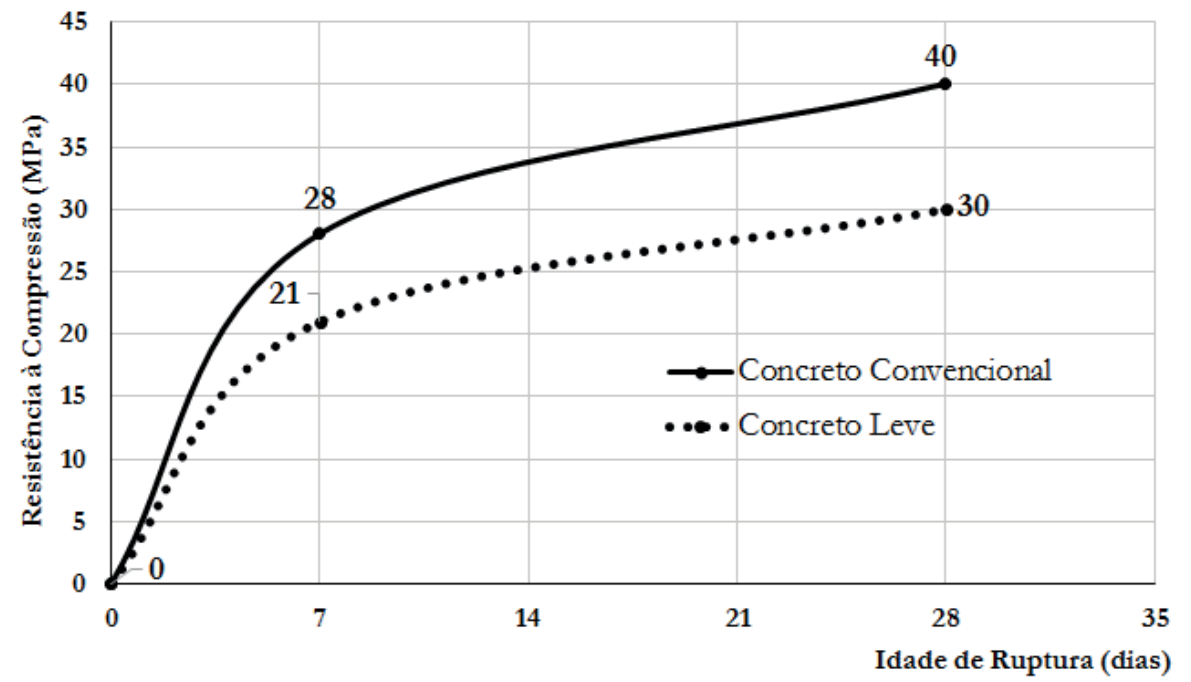

Figura 3: Curvas de variação da resistência à compressão em função da idade de ruptura para os concretos convencional e leve com argila expandida sem proteção epoxídica.

Os produtos das dosagens do concreto convencional e do concreto leve com argila expandida atenderam aos valores de resistência característica à compressão (Fck) (concreto classe $\mathrm{C} 40$ e classe $\mathrm{C} 30$, respectivamente, relação água/cimento de 0,5) estabelecidos pela ABNT NBR 6118:2014 para concretos a serem submetidos a uma agressividade de classe III [11].

Os ensaios de compressão realizados em corpos de prova cilíndricos de concreto demonstraram que, em concretos com agregado leve, a seção de ruptura passou através do agregado, indicando que o agregado leve foi limitador da resistência à compressão (Figura 4) [06, 07].

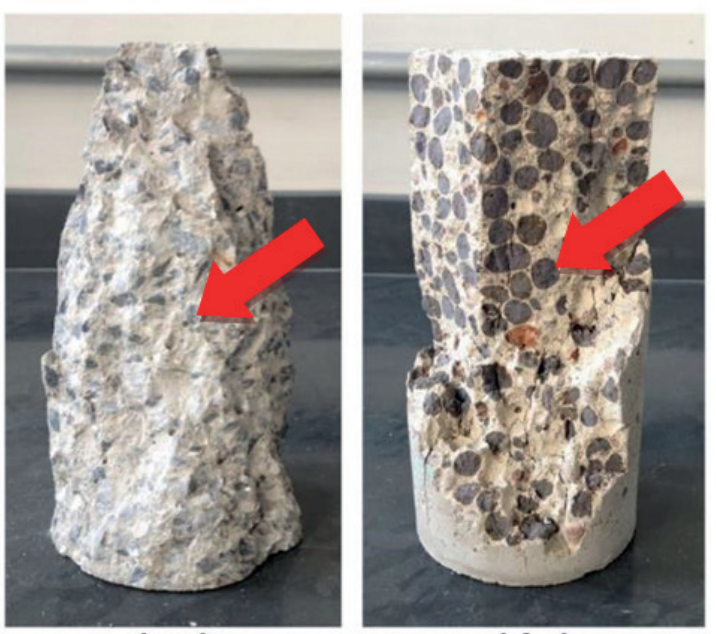

Figura 4: Seção de ruptura do concreto convencional (a) e do concreto leve (b). 
Observa-se que, no concreto convencional, a fratura contorna o agregado graúdo oriundo de rocha gnáissica, passando pela zona de transição e pela matriz de cimento. Por outro lado, no concreto leve, a fratura passa através do próprio agregado devido à maior resistência da pasta e da argamassa que o envolve.

A degradação superficial dos concretos foi avaliada aos 43 dias, inicialmente por meio de inspeção visual dos corpos de prova, antes e após o ataque por imersão em ácido sulfúrico 2,5\%, durante 7 dias. Tanto o concreto convencional quanto o concreto leve apresentaram desgaste e esfarelamento superficial e exposição do agregado graúdo em toda sua superfície, conforme mostra a Figura 5.

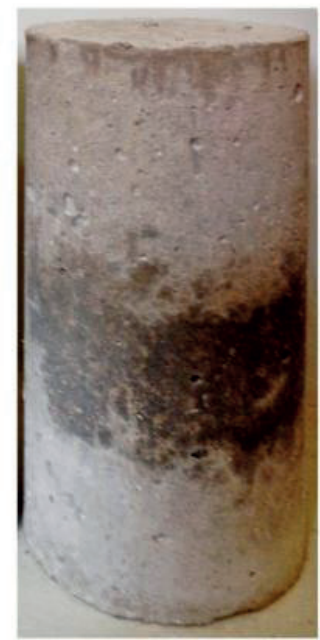

(a)

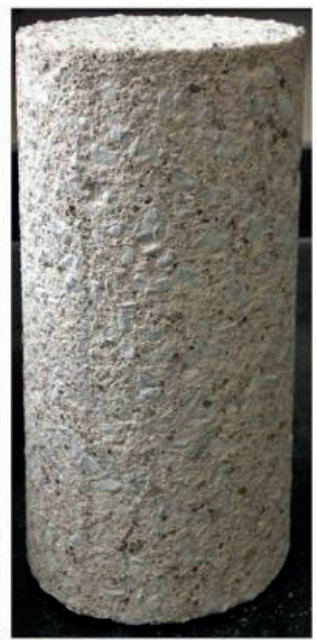

(b)

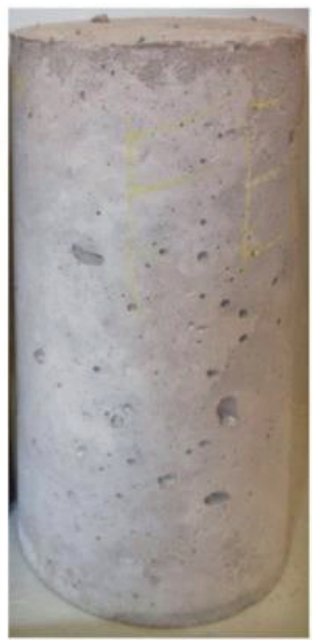

(c)

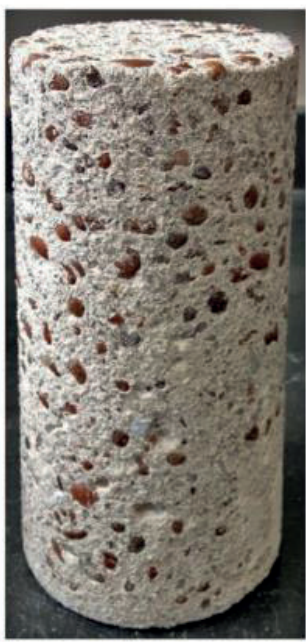

(d)

Figura 5: Corpos de prova $5 \times 10 \mathrm{~cm}$ de concreto sem proteção: concreto convencional antes do ataque (a); concreto convencional após ataque (b); concreto leve antes do ataque (c); concreto leve após ataque (d).

A degradação ocasionada pelo ataque promoveu a exposição dos agregados por expansão ou fissuração, promovendo efeitos danosos; como o aumento da porosidade do concreto que pode ser comprovada através dos resultados do ensaio de absorção de água e desplacamento que pode ser comprovado pela exposição dos agregados após o ataque e também pelo resultado do ensaio de perda de massa $[6,14,15]$.

A proteção superficial com tinta epoxídica resultou em uma perceptível minimização dos efeitos do ataque químico, tanto para o concreto convencional quanto para o concreto leve, apresentando apenas pequenas bolhas superficiais, conforme ilustra a Figura 6.

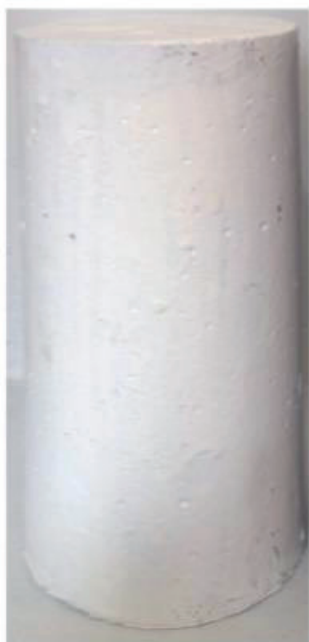

(a)

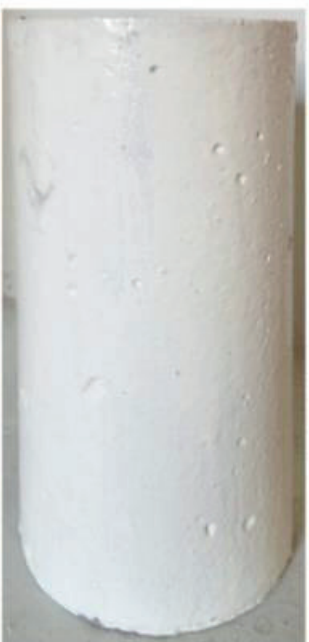

(b)

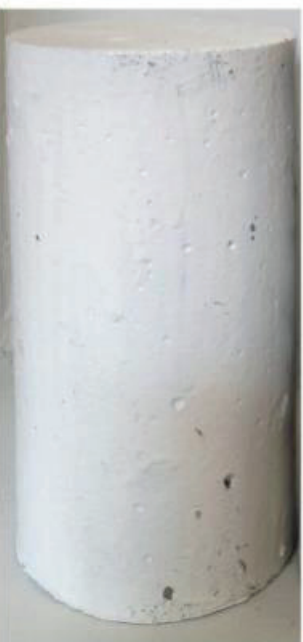

(c)

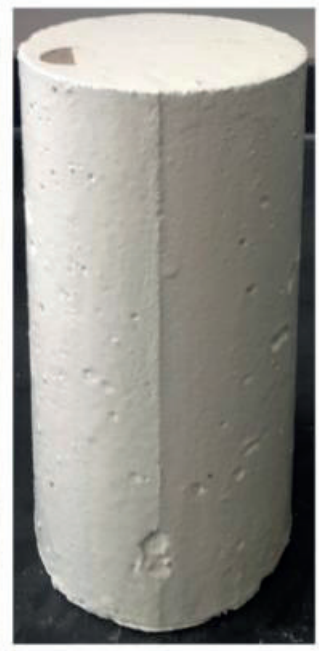

(d)

Figura 6: Corpos de prova $5 \times 10 \mathrm{~cm}$ de concreto com proteção epoxídica: concreto convencional antes do ataque (a); concreto convencional após ataque (b); concreto leve antes do ataque (c); concreto leve após ataque (d). 
A proteção epoxídica comprova ser efetiva devido ao fato de possuir boa resistência a ataques químicos, como os causados pela solução de $\mathrm{H}_{2} \mathrm{SO}_{4}$, boa aderência ao concreto e por reduzir a entrada de agente agressivo [16].

Na Figura7, são apresentados os resultados dos ensaios de absorção de água por imersão, segunda a ABNT NBR 9778:2009, do concreto convencional e do concreto leve, sem e com proteção, antes e após ataque por ácido sulfúrico [29]. Os resultados apresentados são médios, provenientes de 6 resultados individuais para cada tipo de amostra, antes e após o ataque por ácido sulfúrico.

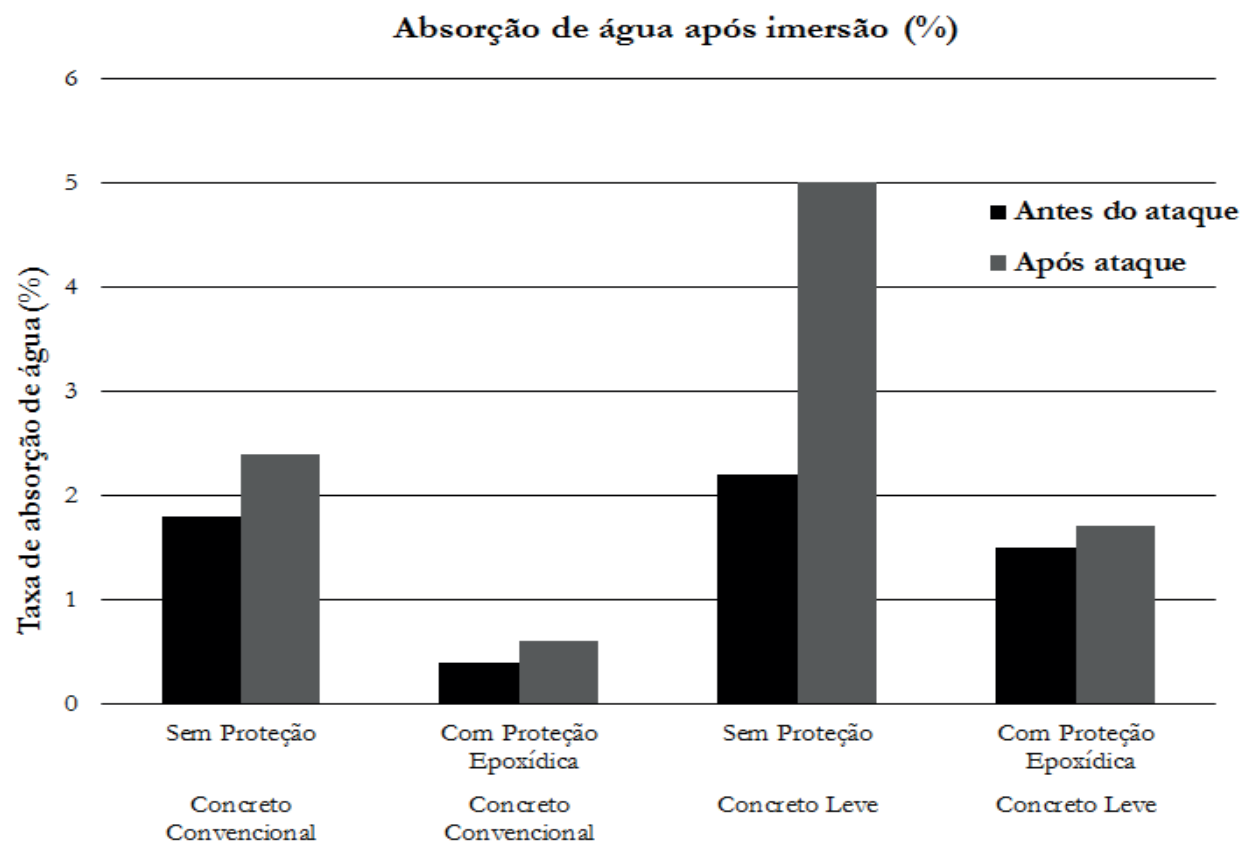

Figura 7: Taxa de absorção de água do concreto convencional e do concreto leve sem e com proteção epoxídica, antes e depois do ataque por $\mathrm{H}_{2} \mathrm{SO}_{4}$.

Os resultados de absorção do concreto leve, sem proteção, foram inferiores a 10\%. Este valor corresponde ao limite crítico para concretos duráveis preconizado na literatura [3].

Os resultados médios dos ensaios de absorção realizados após o ataque permitem verificar uma nítida diminuição dos índices de absorção dos concretos protegidos em relação aos concretos não protegidos, de $2,4 \%$ para $0,6 \%$ no concreto convencional e de $5 \%$ para $1,7 \%$ no concreto leve, evidenciando que as proteções contribuem para o controle da penetração do ácido sulfúrico e dos processos de deterioração dos concretos.

Os resultados mostraram que as pinturas epoxídicas foram mais importantes no caso do uso do concreto leve em situação de ataque por $\mathrm{H}_{2} \mathrm{SO}_{4}$ A perda de massa média após ataque por imersão em ácido sulfúrico 2,5\%, durante 7 (sete) dias, é apresentada na Figura 8. Os resultados apresentados são médios, provenientes de 8 resultados individuais para cada tipo de amostra.

Os resultados de perda de massa são coerentes com os resultados de absorção e de análise visual da degradação superficial, uma vez que as perdas de massa foram diminuídas com a aplicação da pintura epoxídica, sendo que a proteção se mostrou mais necessária no concreto leve. 
Perda de massa $(\%)$

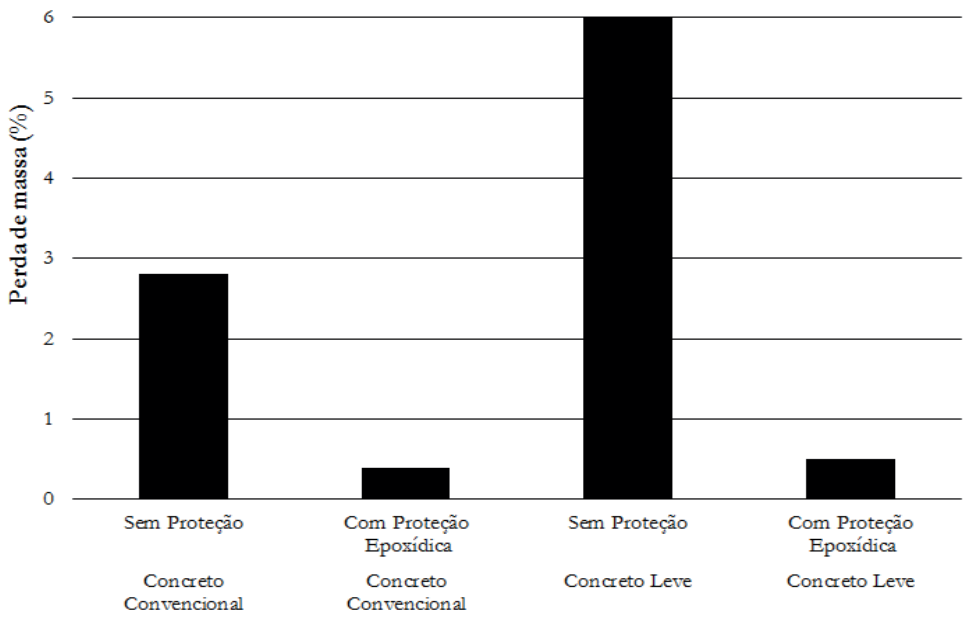

Figura 8: Perda de massa antes e após ataque por $\mathrm{H}_{2} \mathrm{SO}_{4}$ nos concretos convencional e leve.

A perda de resistência à compressão média dos corpos de prova de concreto, antes e após ataque por imersão em ácido sulfúrico 2,5\%, está apresentada na Figura 9. Os resultados apresentados são médios, provenientes de 8 resultados individuais para cada tipo de amostra, antes e após o ataque por ácido sulfúrico.

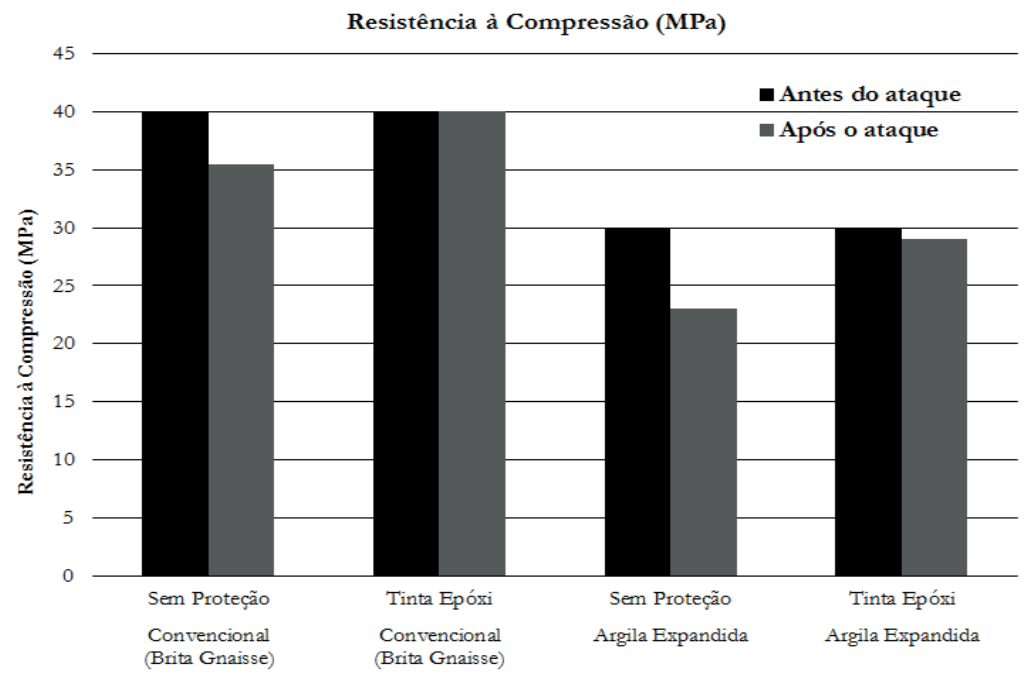

Figura 9: Resistência à compressão dos concretos após o ataque por $\mathrm{H}_{2} \mathrm{SO}_{4}$, com e sem proteção

Apesar das avaliações visuais de degradação e dos ensaios de absorção e perda de massa mostrarem pequenos danos no caso do ataque aos concretos convencional e leve protegidos com a pintura epoxídica, os resultados de resistência à compressão comprovam que os danos foram superficiais e promoveram baixas alterações de resistência quando comparado aos resultados dos concretos sem proteção. Nos concretos convencional e leve sem proteção, os processos de degradação contribuíram para a diminuição da resistência à compressão, o que indica que a perda de massa promovida pelo ataque ácido, reduz a resistência à compressão do concreto e amplia a taxa de absorção de água, tornando o composto mais vulnerável a ataques externos.

\section{CONCLUSÃO}

Os ensaios realizados permitiram avaliara tinta epoxídica como camada protetora em concreto $\mathrm{C} 40$ submetido a uma agressividade ambiental de classe III, através de ensaios de resistência à compressão, de absorção de água, de perda de massa e por inspeção visual de corpos de prova sem e com proteção epoxídica, antes e após ataque por $\mathrm{H}_{2} \mathrm{SO}_{4}$.

A inspeção visual demonstra que os corpos de prova com proteção apresentam uma nítida diminuição da perda de 
coesão da pasta causada pelo ataque e que o concreto sem proteção, submetido a ataque ácido, apresenta um esfarelamento de sua superfície, deixando os agregados graúdos expostos.

A tinta epoxídica se mostrou mais necessária para o concreto leve e sua resistência a agentes químicos reduzindo a penetração do ácido sulfúrico tanto no concreto convencional quanto no concreto leve, o que foi suficiente para minimizar os efeitos negativos do ataque ácido na taxa de absorção de água, na perda de massa e na perda de resistência.

Portanto, agregados leves de argila expandida são uma alternativa viável para confecção de concretos estruturais leves do ponto de vista de desempenho mecânico, já que os concretos confeccionados com agregados leves de argila expandida apresentaram características similares aos confeccionados com agregados convencionais. Além disso, o estudo demonstra que a proteção superficial de concretos leves com tinta epoxídica, pode garantir a durabilidade dos concretos leves estruturais confeccionados com argila expandida, atendendo aos requisitos de durabilidade e sustentabilidade das construções.

\section{REFERÊNCIAS}

[1] NEVILLE, A.M. Propriedades do concreto. 5 ed., Porto Alegre, Bookman, 2016.

[2] RIBEIRO, C. C., PINTO, J.D.S., STARLING, T. Materiais de Construção Civil, $4^{\mathrm{a}}$ ed. Revisada. Belo Horizonte, Editora UFMG, 2015.

[3] SANTIS, B. C., ROSSIGNOLO, J. A. "Influência dos agregados leves de argila calcinada nas propriedades mecânicas de concretos estruturais”, Revista Matéria, v. 20, n. 02, pp. 399-406, 1996.

[4] ROSSIGNOLO, J. A. Concreto leve estrutural: Produção, propriedades, microestrutura e aplicações,1 ed., São Paulo, Pini, 2009.

[5] SILVA, E. Q., BORJA, E. V. Concreto leve a base de argila expandida: Propriedades e aplicabilidade para alvenaria de casas populares. Centro federal de educação tecnológica do rio grande do norte, 2008.

[6] MEHTA, P. K., MONTEIRO, P. J. M., Concreto: Estrutura, Propriedades e Materiais.3. ed., São Paulo, IBRACON, 2008.

[7] ISAIA, G.C. Concreto: ensino, pesquisa e realizações. 1. ed., São Paulo, IBRACON, 2005.

[8] CHANDRA, S., BERNTSSON, L. Lightweight aggregate concrete-Science, technology, and applications. 1. ed., Nova York, William Andrew, 2002.

[9] AMERICAN CONCRETE INSTITUTE. ACI 213R-14: Guide for Structural Lightweight-Aggregate Concrete. Farmington Hills, 2014.

[10] ASSOCIAÇÃO BRASILEIRA DE NORMAS TÉCNICAS. NBR NM 35:Agregados leves para concreto estrutural. Rio de Janeiro, 1995.

[11] ASSOCIAÇÃO BRASILEIRA DE NORMAS TÉCNICAS. NBR 6118: Projeto de estruturas de concreto. Rio de Janeiro, 2014.

[12] HERVE, E. N. A nova engenharia do concreto, Comunidade da Construção, 2005.

[13] HELENE, P.R. L. Manual para reparo, reforço e proteção de estruturas de concreto, $2^{\text {a }}$ ed. São Paulo, PINI, 1992.

[14] HELOÍSA, P. M. Ação de alguns agentes agressivos sobre concretos amassados com diferentes tipos de cimentos brasileiros. 2001. 169 p. Dissertação - ESCOLA POLITÉCNICA, USP, São Paulo, 2001.

[15] HELOÍSA, P. M.; PAZINI, E.; HELENE, P. Boletim Técnico - Avaliação da influência de alguns agentes agressivos na resistência à compressão de concretos amassados com diferentes tipos de cimentos brasileiros - USP, São Paulo, n. 286, $17 \mathrm{p}$.

[16] OLIVEIRA, M. M. Tecnologia da conservação e da restauração - materiais e estruturas: um roteiro de estudos. 4 ed., Salvador, Scielo, 2011.

[17] ASSOCIAÇÃO BRASILEIRA DE NORMAS TÉCNICAS. NBR NM 23:Cimento Portland - determinação da massa especifica. Rio de Janeiro, 2001.

[18] ASSOCIAÇÃO BRASILEIRA DE NORMAS TÉCNICAS. NBR 11579:Cimento Portland - determinação da finura por meio da peneira $75 \mu \mathrm{m}\left(\mathrm{n}^{\circ} 200\right)$ - Método de ensaio. Rio de Janeiro, 2013.

[19] ASSOCIAÇÃO BRASILEIRA DE NORMAS TÉCNICAS. NBR NM 76:Cimento Portland - determinação da finura pelo método de permeabilidade ao ar (Método de Blaine). Rio de Janeiro, 2016. 
[20] ASSOCIAÇÃO BRASILEIRA DE NORMAS TÉCNICAS. NBR 11582:Cimento Portland - determinação da expansibilidade Le Chatelier. Rio de Janeiro, 2016.

[21] ASSOCIAÇÃO BRASILEIRA DE NORMAS TÉCNICAS. NBR NM 45:Agregados - determinação da massa unitária e volume de vazios. Rio de Janeiro, 2006.

[22] ASSOCIAÇÃO BRASILEIRA DE NORMAS TÉCNICAS. NBR NM 52:Agregados - determinação da massa específica de agregados miúdos por meio do frasco de Chapman. Rio de Janeiro, 2003.

[23] ASSOCIAÇÃO BRASILEIRA DE NORMAS TÉCNICAS. NBR NM 248:Agregados - determinação da composição granulométrica. Rio de Janeiro, 2003.

[24] ASSOCIAÇÃO BRASILEIRA DE NORMAS TÉCNICAS. NBR NM 53:Agregados - determinação da absorção e massa especifica do agregado graúdo. Rio de Janeiro, 2003.

[25] ASSOCIAÇÃO BRASILEIRA DE NORMAS TÉCNICAS. NBR 7211:Agregados para concreto. Rio de Janeiro, 2009.

[26] ASSOCIAÇÃO BRASILEIRA DE NORMAS TÉCNICAS. NBR 5738:Concreto - Procedimento para moldagem e cura de corpos de prova. Rio de Janeiro, 2016.

[27] ASSOCIAÇÃO BRASILEIRA DE NORMAS TÉCNICAS. NBR 5739:Concreto - ensaio de compressão de corpos de prova cilíndricos. Rio de Janeiro, 2007.

[28] VEDACIT, Impermeabilizantes. Manual técnico: Recuperação de Estrutura, 48ª ed. São Paulo, 2016.

[29] ASSOCIAÇÃO BRASILEIRA DE NORMAS TÉCNICAS. NBR 9778:Argamassa e concreto endurecido - Determinação da absorção de água por imersão - Índice de vazios e massa específica. Rio de Janeiro, 2009.

[30] ASSOCIAÇÃO BRASILEIRA DE NORMAS TÉCNICAS. NBR 13583: Cimento Portland - Determinação da variação dimensional de barras de argamassa de cimento Portland expostas à solução de sulfato de sódio. Rio de Janeiro, 2014.

\section{ORCID}

Felipe de Souza Abreu Carmen Couto Ribeiro Joana Darc Silva Pinto Danielle Meireles Oliveira Sidnea Eliane Campos Ribeiro Ênio José Pazini Figueiredo https://orcid.org/0000-0003-3174-3387

https://orcid.org/0000-0002-6698-9865

https://orcid.org/0000-0003-2946-0206

https://orcid.org/0000-0003-4379-5096

https://orcid.org/0000-0001-7875-9314

https://orcid.org/0000-0002-2765-750X 